\title{
Information Cascades: Replication and an Extension to Majority Rule and Conformity-Rewarding Institutions
}

\author{
By Angela A. Hung and Charles R. Plott*
}

The research reported here was originally motivated by the results of Lisa R. Anderson and Charles A. Holt (1997), who demonstrated the existence of cascades in sequences of individual decisions. In certain environments the decisions of individuals tended to reflect only the decisions of those who went before them and did not reflect the information they held privately. Our first question was whether the results they reported would replicate.

Reflections on the problem led us to realize that the study of cascades is a branch of three strands of research. While these strands of research have similarities, they tend to reflect differences about the principles governing behavior. The first strand of research is the conformity or "herding" research which is focused primarily on models that might explain similarities in individual choices or interdependencies of preferences. Typically the phenomenon is called "herds," "fads," or "conformity," which reflects a concern with "incorrect" or "wrong" cascades, despite the recognition that cascades can result from rational, Bayesian-Nash behavior. Even though the literature is less dramatic, it is easy to liken the behavior to lemmings in which each follows the one ahead over a cliff and falls to its death, all of which suggests that the behavior is viewed as being somewhat dysfunctional.

Aspects of the second strand of research, the

\footnotetext{
*Hung: H. John Heinz III School of Public Policy and Management, Carnegie Mellon University, 5000 Forbes Avenue, Pittsburgh, PA 15213; Plott: Division of the Humanities and Social Sciences, M/C 228-77, California Institute of Technology, Pasadena, CA 91125. The financial support of the National Science Foundation and the Laboratory of Experimental Economics and Political Science is gratefully acknowledged. We are also deeply appreciative of the collaboration of David Winkler, who developed the software programs and helped extensively with the experiments. We benefited from conversations with Colin Camerer, David Grether, Richard McKelvey, Anthony Ziegelmeyer, and participants at the Economic Science Association meetings in October 1998, as well as comments from the anonymous referees.
}

information aggregation literature, are frequently employed in the first strand. However, when viewed independently as an information aggregation issue, the topic of cascades is approached differently and aspects of market stability also become involved. ${ }^{1}$ Cascade behavior is a Pareto improvement over behavior in which individuals base decisions only on their private information, since a cascade reflects an integration of more private information than any single individual possesses. However, all information is not integrated into a cascading system and the pattern of decisions themselves do not summarize and publicize a summary of private information as prices can do in markets. The phenomena involves an information externality or public good inefficiency problem fostered by the nature of the decision-making institutions and environment. The private information of those who make decisions, after the first person or two, is not made available to those who follow. Some of the early decision makers fail to contribute to the "public good" of pooled information. ${ }^{2}$ Thus, the information aggregation literature leads naturally to questions about the role of institutions and the efficiency of the system in both an allocation sense and in an information sense.

The third strand of literature also leads to issues about institutions as well as the underlying reasons for the observed patterns of behavior. Cascades were observed many years ago by social psychologists, although they were given other names. Psychologists distinguished between conformity due to integration of private

\footnotetext{
${ }^{1}$ Issues of market instability are closely related to the cascade phenomena by virtue of the interdependence of preferences and beliefs. See Gary S. Becker (1991), Edi Karni and Dan Levine (1994), and Plott and Jared Smith (1999).

${ }^{2}$ For example, Abhijit V. Banerjee (1992) discusses "herd externalities," and Sushil Bikhchandani et al. (1998) discuss the positive externality of revealing one's private signal.
} 
information with information inferred from others' behavior, "informational social influence," and conformity that results from an internal motivation to conform to the perceived norms of the group, "normative social influence." Normative social influence includes the possibility that individuals sometimes find themselves in situations where they will be punished by the group if they do not conform. Conformity might be rewarding regardless of the information that exists.

The experiments reported here can be viewed as a study of the relationships among institutions and the "cascade phenomenon." The experiments can also be viewed as a narrowing of the potential theories of behavior while using the study of specific institutions to facilitate the task. The experiments focused on three different types of institutions consisting of different rules and organization. (1) Agents were rewarded according to whether their announced decision was right or wrong. This organization is the "individualistic institution" studied by Anderson and Holt (1997). (2) Agents were rewarded according to whether a majority of announced decisions were right or wrong under the "majority rule institution." (3) Agents are rewarded more according to whether their personal announced decision was the same as the majority decision than they were rewarded for a correct decision under the "conformity-rewarding institution."

The paper poses three fundamental questions. First, do the results of Anderson and Holt replicate? The second question is related to the organization of the decision process, the rules that are in place governing individual rewards and incentives. Do the rules make a difference? Third, can the influence of the organization be detected in models of individual decisions? That is, can we further narrow the class of possible explanations for cascade behavior? The candidates include (i) a preference for conformity (ii) Bayesian-Nash equilibrium behavior, (iii) nonequilibrium Bayesian behavior, and (iv) various heuristics. Anderson and Holt were able to reject (iv) in favor of the other classes,

\footnotetext{
${ }^{3}$ A good introduction to the way psychologists have studied this problem is contained in Eliot Aronson, et al. (1997).
}

but in their experiments they were unable to say which, if any, of the others might be operating to account for the data. Part of this paper is to further narrow the class of potential explanations with respect to experiments.

Our results are outlined as follows. First, the Anderson and Holt observation that information cascades will occur in particular environments is strongly upheld by the experiments we report. ${ }^{4}$ When the individual's payoff is determined by his/her own announced decisions, then individuals tend to treat their private signal as irrelevant and follow the trend of their predecessors, if a clear pattern is present. Second, we find that relative to the individualistic institution studied by Anderson and Holt, the predominance of information cascades sharply decreases with the change in institution to a majority rule process. The data reported here are consistent with the data from experiments of majority rule jury decisions studied by Richard D. McKelvey and Thomas R. Palfrey (1998a). Furthermore, the tendency to cascade increases when the conformity-rewarding institution is implemented. Following David M. Grether (1980), we begin to explore the quantitative effects of changes in institution on the nature of individual decisions. While the model we explore is clearly incomplete, it provides a framework within which individual decisions are understandable. Finally, we can rule out explanations (i), a preference for conformity, and (iii), nonequilibrium Bayesian behavior, as explanations for cascade behavior.

The paper is divided into seven sections. Section I discusses the institutions. Section II is the experimental design. Section III is an outline of measures of information production. This is the information that participants in the process and an outside observer of the process might infer from behavior. Section IV is a model that reflects how individuals use information. While we have no complete theory of individual behavior, this section develops a model that facilitates interpretations. Section V summarizes interpretations of the model introduced in the previous section. Section VI summarizes the results, and Section VII concludes.

\footnotetext{
${ }^{4}$ The Anderson and Holt results have also been replicated by Marc Willinger and Anthony Ziegelmeyer (1998).
} 


\section{Institutions: The Rules and Procedures}

In all of the institutions studied here the technology of communication is the same. Each agent was given an independent, private signal about which of two states had been chosen by a random draw. After receiving the private signal, each agent was called upon according to a randomly determined sequence to announce a decision about the state. That is, the individual's decision was publicly announced before a decision was made by the succeeding individual. Thus, at the time of personal decision each agent had a private signal and also knew the decisions of all preceding agents. The decision of an individual was not necessarily a report of the individual's private information, but instead was an announcement that would have an influence on the individual's payoff. The agent was aware of the rules that governed the relationships among announced decisions and individual payoffs. He also knows that all decision makers operate under the same conditions. Thus, by changing the rules while maintaining the communications technology, we are able to gain insights about the relationships among information derived from the behavior of others, incentives, and private information.

The Individualistic Institution.-The first set of rules, which we call the "individualistic institution," are those studied by Anderson and Holt. When individuals make decisions they have their own private information plus the information contained in the decisions of those who made decisions in the past. Furthermore, aside from information (externality) issues, the effects of an individual's decisions are confined to the individual who makes the decision. Examples include models of job search, financial markets, fads, and herd behavior (see Bikhchandani et al., 1992 or 1998 for an overview of applications).

The Majority Rule Institution.-The second set of rules is the collective decision rule of majority rule. The frequency with which majority rule is used to make important decisions makes it a natural candidate for study. The individual announced decisions become votes which tie the consequences of individuals together in the sense that all individuals must abide by the same decision and that is the de- cision of a majority. Individuals are given the latitude of how they vote in the context of this group decision but they cannot make independent payoff relevant decisions apart from the vote. The study of majority rule has theoretical interest. In particular it is nonmanipulable so there is a presumption that the "best information" will be produced.

Conformity-Rewarding Institution.-The third rule is a rule in which there are special incentives to conform to the decision of a majority. In this environment individuals have an incentive to be right but they have a bigger incentive to not deviate from the decisions of others.

Pressures to conform to group behaviors have been widely discussed for many decades. For example, the early literature on cascades was viewed as a study of conformity resulting from the nature of groups and social interaction (Solomon E. Asch, 1958). In addition, groups are viewed as "punishing" deviates thereby providing private incentives for individuals to conform to the patterns of behavior of others in the group (Stanley Schachter, 1951).

Political processes and perhaps even managerial organizations involve themselves in institutions that result in the punishment of individuals whose opinions deviate from the group. For example, the punishments can exist in the form of distrust or lack of confidence in those whose opinions and voting patterns are different from those of the majority. Promotions and standing within an organization can be affected. In some cases, the pressure to conform can be tied closely to procedures such as in the case of grand jury procedures in which charges of perjury may result from testimony that differs from the testimony of others. Thus, personal rewards and punishments are closely tied to consistency with the decisions and recorded opinions of others, independent of whether such decisions and opinions are closely tied to the truth. As can be seen, in some cases the incentives to conform are natural properties of individual preferences, and in other cases they are derived from the properties of the institutions.

\section{Experimental Design}

Four experiments were conducted in the Laboratory for Experimental Economics and Polit- 
TABle 1 -Experimental Design

\begin{tabular}{|c|c|c|c|c|c|}
\hline \multirow[b]{2}{*}{ Experiment } & \multicolumn{3}{|c|}{ Periods in which institution is in effect } & \multirow[b]{2}{*}{ Payoffs } & \multirow[b]{2}{*}{ Computer } \\
\hline & Individualistic & Majority & Conformity & & \\
\hline 1 & $1-28$ & & & $\$ 2,0$ & No \\
\hline 2 & $1-10,26-36$ & $11-25$ & & $\$ 2,-2$ & Yes \\
\hline 3 & $11-25$ & $1-10,26-38$ & & $\$ 1,-1$ & Yes \\
\hline 4 & $16-30,46-55$ & & $1-15,31-45$ & $\$ 0.75,-0.75 / \$ 0.25,-0.25$ & Yes \\
\hline
\end{tabular}

ical Science at Caltech. Each experiment had ten Caltech undergraduates as subjects. The experiments consisted of $28-55$ periods and lasted for about one and a half hours. The procedures described below were adapted from those used by Anderson and Holt (1997). Some changes reflect employment of computers. The instructions used in the experiments are available upon request. The nature of incentives were changed to save money. The four experiments are summarized in Table 1.

Experiment 1 most closely resembles the experiments of Anderson and Holt. In experiment 1 , the urn that was to be used each period was randomly predetermined. Urn A contained two RED balls and one WHITE ball, and urn B contained two WHITE balls and one RED ball. Each period, the contents of the chosen urn were emptied into an unmarked container. Subjects were then approached in a random order by the experimenter and would make one private draw, with replacement. After seeing the draw, the subject was asked to record his decision on a record sheet and also the color of the draw. The experimenter then announced the decision, and all the subjects would record this decision on their record sheets. The process was repeated until all subjects had made decisions, at which time the actual urn used was announced. Subjects were asked to record their earnings: $\$ 2$ if their decision was correct, and $\$ 0$ otherwise. Experiment 1 consisted of 28 periods.

In experiment 2 , the procedure was the same, except that subjects interacted with computer terminals rather than the experimenter. A subject is "approached" by the computer and given a draw by an announcement of "Your draw is WHITE" or "Your draw is RED." After seeing the draw, subjects were then asked to enter their decision into a box on the screen. All the sub- jects would then see this decision on their screens. As before, subjects were asked to record their draws, their own decisions, and the decisions of others on a record sheet. This process was repeated until all subjects had made decisions, at which time the actual urn used would appear on the subjects' screens. In periods 1-10 and 26-36, the "individualistic" periods, subjects would also see their payoff on the screen, $\$ 2$ for a correct decision, and $-\$ 2$ otherwise. In periods 11-25, the "majority" periods, subjects would see the "group decision" as well as their payoff on the screen. The group decision was determined by majority rule, with ties broken randomly. Subjects were paid $\$ 2$ for a correct group decision, and -\$2 for an incorrect decision, regardless of their own decision. ${ }^{5}$

Experiment 3 differed from experiment 2 in that periods 1-10 and 26-38 were "majority" periods, and periods 11-25 were "individualistic" periods. Subjects were paid $\$ 1$ for a correct decision or correct group decision, and $-\$ 1$ otherwise.

In experiment 4, we introduce the "conformity-rewarding" institution. In these rounds, the payoff to a subject is determined by whether her private decision is correct, and also if her private decision matches the group decision, where once again, the group decision is determined by majority rule. Subjects are paid $\$ 0.25$ for a correct private decision and $-\$ 0.25$ for an incorrect decision, and they are paid $\$ 0.75$ for a

\footnotetext{
${ }^{5}$ In the "individualistic" rounds, the instructions read: "You earn \$2 for each decision that matched the urn that was actually used. Otherwise you lose $\$ 2$." In the "majority rule" periods, the instructions regarding earnings read: "Your earnings are determined as follows: If the majority of the group decisions match the urn that was actually used, then you earn $\$ 2$. Otherwise, you lose $\$ 2$."
} 
private decision that matches the group decision and $-\$ 0.75$ for a private decision that does not match the group decision. ${ }^{6}$

\section{Three Measures of System Performance}

The literature seems to assume that cascades indicate poor information production and use within the system, which leads to poor system performance. However, this assumption is not entirely correct. Cascade behavior can result in better decisions than purely individualistic decisions because it does involve aspects of information aggregation. Thus in order to assess such possibilities, we explore two related measures of systemic performance in addition to the traditional measure of cascades: the efficiency of systemic decisions and the quality of information production.

Traditional Information Cascades.-The consensus in the literature is that a cascade is defined by a sequence of individuals whose decisions do not depend on their private information (see Bikhchandani et al., 1992 or Lones Smith and Peter Sørensen, 2000). Following Anderson and Holt, we add the additional stipulation (that is usually implicit in the definition) that a cascade is defined by an established pattern of decisions together with the presence of subsequent decisions that are consistent with this pattern, but inconsistent with the private draws.

Efficiency of Systemic Decisions.-The concept of efficiency rests on the concept of the fully informed decision. The fully informed decision is the decision that an expected utility maximizer would make if he had access to all private information in the system, the entire sequence of true signals.

The systemic decision is a function of the subjects' actual decisions. For the individualistic and conformity-rewarding institutions, the

\footnotetext{
${ }^{6}$ For the "conformity-rewarding" institution, the instructions read: "Your earnings are determined as follows: If your decision matches the urn that was actually used, then you earn $\$ 0.25$. Otherwise you lose $\$ 0.25$. In addition, if your decision matches the majority of the group's decisions, then you earn an additional $\$ 0.75$. Otherwise you lose an additional \$0.75."
}

systemic decision is the vector of the individuals' announcements. However, for the majority rule institution the individual announcements are, in effect, votes that determine the unique systemic decision.

Let $a_{i}$ be individual $i$ 's announcement in a given period for $i \in\{1, \ldots, 10\}$. The systemic decision in that period is a function of the vector of the individual's announcements, $G\left(a_{1}, \ldots, a_{10}\right)$, where the function $G$ depends on the institution:

$$
\begin{aligned}
& G\left(a_{1}, \ldots, a_{10} \mid \text { individualistic }\right)= \\
& \quad=G\left(a_{1}, \ldots, a_{10} \mid \text { conformity rewarding }\right)= \\
& \quad=\left(a_{1}, \ldots, a_{10}\right) . \\
& \begin{aligned}
G & \left(a_{1}, \ldots, a_{10} \mid \text { majority rule }\right)= \\
\quad & (\alpha, \ldots, \alpha),
\end{aligned}
\end{aligned}
$$

where $\alpha$ is the majority winner of the announcements in the period. In the case of a tie, the majority winner is chosen randomly.

The efficiency of systemic decision is measured each period as the proportion of the systemic decisions that match the fully informed decision. ${ }^{7}$ The efficiency of systemic decisions in the period is:

$$
\text { efficiency }=\frac{\sum_{i=1}^{10} 1\left\{G_{i}=a^{*}\right\}}{10}
$$

where $1\{\cdot\}$ is the indicator function and $G_{i}$ is individual $i$ 's component of the systemic decision in the period, and $a^{*}$ is the fully informed decision of the period.

Information Production Quality.-Another measure of system performance is the amount of the underlying information of the system that is exposed to an outside observer. The concept is taken from economics where informational efficiency is related to whether or not the prices

\footnotetext{
${ }^{7}$ This measure of efficiency is not weighted by the payoffs resulting from correct or incorrect decisions. The focus is on the information alone and not its economic value.
} 
are "fully revealing." Consider an observer who is outside of the decision process and, from only the announcements of the subjects, must make inferences about the true state of the world. Assume that each subject's announcement reflects the state of the world that he thinks is most likely. The outside observer's posterior probabilities of the true state are compared with those of an observer who can observe all the private signals. The information production quality is inversely related to the absolute difference between the posterior probabilities of an outside observer who observes only the entire sequence of announcements and the posterior probabilities of an outside observer who observes the entire sequence of private signals. The best information production quality has a quality of one, and the worst has a quality of zero:

$I P Q=1-\mid \operatorname{Pr}\left(A \mid a_{1}, \ldots, a_{10}\right)$

$$
-\operatorname{Pr}\left(A \mid d_{1}, \ldots, d_{10}\right) \mid
$$

where $a_{1}, \ldots, a_{10}$ is the sequence of announcements in a given period and $d_{1}, \ldots, d_{10}$ is the sequence of private draws in the period.

\section{Information Use: The General Decision Weight Model}

One way to capture the effects of the institution is in terms of individual behavior. We do not have a good understanding of exactly why individuals behave as they do, but the General Decision Weight model will help us detect when they are behaving differently and how their behavior differs under different institutions.

Before announcing an urn, a subject has two sources of information: her private draw, and the announcements of those who preceded her. The General Decision Weight model is constructed on the premise that a subject's announcement is based on these two sources. Given a pattern of announcements, the model allocates weight that a subject places on her public information (the preceding announcements) relative to the weight that she places on her private information in making her announcement.
Let $\mathrm{A}$ be the event that urn $\mathrm{A}$ is the true urn, and $B$ be the event that urn $B$ is the true urn. The relative odds in favor of $\mathrm{A}$ can be expressed as: $P(A) / 1-P(A)=P(A) / P(B)$. Clearly, the odds depend on the information available. Let $x_{i t}=\left(a_{i t}, d_{i t}\right)$ be the information that individual $i$ has at position $t$. Let $a_{i t}$ denote the announcements that individual $i$ has heard at position $t$, and let $d_{i t}$ denote the private draw of individual $i$ at position $t$. Assume $a_{i t}$ and $d_{i t}$ are independent (conditional on a given urn). Then the individual's subjective posterior odds in favor of urn $\mathrm{A}$ are given as:

$$
\begin{aligned}
\frac{P\left(A \mid x_{i t}\right)}{P\left(B \mid x_{i t}\right)}=\frac{P\left(x_{i t} \mid A\right) P(A)}{P\left(x_{i t} \mid B\right) P(B)} & \\
= & \frac{P\left(a_{i t} \mid A\right)}{P\left(a_{i t} \mid B\right)} \frac{P\left(d_{i t} \mid A\right)}{P\left(d_{i t} \mid B\right)} \frac{P(A)}{P(B)} .
\end{aligned}
$$

Take logs and generalize:

$$
\text { (1) } \begin{aligned}
Y_{i t}=\alpha+\beta \ln \left[\frac{P\left(a_{i t} \mid A\right)}{P\left(a_{i t} \mid B\right)}\right] \\
+\gamma \ln \left[\frac{P\left(d_{i t} \mid A\right)}{P\left(d_{i t} \mid B\right)}\right]+u_{i t},
\end{aligned}
$$

where $Y_{i t}=\ln \left[P\left(A \mid x_{i t}\right) / P\left(B \mid x_{i t}\right)\right] ; \alpha, \beta$, and $\gamma$ are unknown scalars; and $u_{i t}$ is a random disturbance. $^{8}$

We do not observe the subjective log odds $Y_{i t}$. If we assume that the individual chooses the urn believed to be most likely, we observe the discrete variable $Y_{i t}^{*}$, which equals one if $Y_{i t}$ is positive (" $\mathrm{A}$ " is announced), and zero otherwise. The parameters of this binary response model may be estimated by maximum likelihood under distributional assumptions on $u_{i t}$, given that the matrix of independent variables is of full rank. ${ }^{9}$

Grether (1980) used this model to study Bayesian updating in a similar experimental

$$
\begin{aligned}
& { }^{8} \text { Note that } \ln \left[\frac{P(A)}{P(B)}\right]=0 \text { because } P(A)=P(B)=\frac{1}{2} \text {. } \\
& { }^{9} \text { For the "private-information" variable, the variable as- } \\
& \text { sociated with the coefficient } \gamma \text {, we assume that subjects are } \\
& \text { Bayesian. That is, if } d_{i t}=R \text {, then } \ln \left[\frac{P\left(d_{i t} \mid A\right)}{P\left(d_{i t} \mid B\right)}\right]
\end{aligned}
$$


setting. Following Grether (1980), we estimate a logit model under the assumption that the disturbances $u_{i t}$ are identically and independently distributed logistic with mean zero. Without further assumptions on this distribution, the parameters $\alpha$, $\beta, \gamma$ are identified only up to an unknown scale. However, identification up to an unknown scale is sufficient for our analysis.

We can interpret the parameter $\beta$ as the weight that an individual places on the public information available when making her decision. Similarly, the parameter $\gamma$ is the weight that an individual places on the private information when making her decision. Therefore, if the individual weighs public information more than private information, then $\frac{\beta}{\gamma}>1$; if he weighs private information more than public information, then $\frac{\beta}{\gamma}<1$.

\section{Measurement Interpretation}

The general decision weight model serves two functions. The first is to capture important elements of individual behavior. The second is to relate behavior to institutional context so that the influence of institutions can be detailed. Four polar cases are of interest. These are interpreted as follows.

Private-Information Revealer.-Suppose everyone's announcement perfectly matches his private draw. In terms of the general decision weight model, if subjects are acting as private-information revealers, we would expect to find that $\beta$ is not significantly different from zero.

$$
\begin{aligned}
& =\ln \left[\frac{\frac{2}{3}}{\frac{1}{3}}\right]=\ln 2 \text { and if } d_{i t}=W \text {, then } \ln \left[\frac{P\left(d_{i t} \mid A\right)}{P\left(d_{i t} \mid B\right)}\right] \\
& =\ln \left[\begin{array}{c}
\frac{1}{3} \\
\frac{2}{3}
\end{array}\right]=-\ln 2 . \\
& \text { The "public-information" variable is calculated using the } \\
& \text { following formula: if } n_{i t} \text { and } m_{i t} \text { are the number of "urn A" } \\
& \text { and "urn B" announcements, respectively, that individual } i \\
& \text { has heard when he is called upon to make his report his } \\
& \text { decision at position } t \text {, then } \ln \left[\frac{P\left(a_{i t} \mid A\right)}{P\left(a_{i t} \mid B\right)}\right]=\ln \left[\frac{2^{n_{i t}}}{2^{m_{i t}}}\right]= \\
& \left(n_{i t}-m_{i t}\right) \ln 2 .
\end{aligned}
$$

Public-Information Follower.-If the announcement of a subject other than the first person perfectly matches the public information available at the time, then at an individual level, we would expect to see little weight being put on private information; that is, we would expect to find that $\gamma$ is not significantly different from zero.

Naive Bayesians.-Suppose subjects are "naive Bayesians" in the sense that the subjects take into account both private and public information in making their announcements, but this is not common knowledge. An individual believes that the announcements that he has heard perfectly match the private draws of his predecessors. However, his own decision is based solely on his posterior subjective probabilities that are updated every period using Bayes' Law, taking into account both private and public information. These individuals place equal weight on public and private information. If the subjects act as naive Bayesians, then the hypothesis $\beta=\gamma$ can not be rejected.

Strategic Players.-Consider subjects who are strategic: they respond to their incentives, they take into account both public and private information before making their announcements, there is a nonzero probability that they may make errors and they believe that other subjects behave the same way. ${ }^{10}$ This pattern of behavior is hard to detect unless an institutional comparison is made.

In the individualistic institution, subjects place more weight on private than on public information for two reasons. First, there is some probability that previous announcements reflect some error. Second, because other subjects are acting strategically as well, the announcements do not perfectly reveal private signals. In fact, they realize that once a cascade has started, subsequent announcements which follow the cascade reveal no new information. For strategic players in the individualistic institution, the hypothesis that $\frac{\beta}{\gamma}<1$ can not be rejected.

\footnotetext{
${ }^{10}$ Their behavior is essentially Bayesian-Nash equilibrium behavior, but with Quantal Response equilibrium-type errors. See McKelvey and Palfrey (1998b). Anderson and Holt (1997) estimate this sort of model, where errors are assumed to be distributed according to the logistic distribution.
} 
The majority rule mechanism, as mentioned above, is an incentive-compatible mechanism. In the context of a majority rule decision-making system, given a belief that others are doing the same, it is in the subjects' best interest to announce the state of the world reflected by their private information alone. ${ }^{11}$ Therefore, strategic players should act as private-information revealers in the majority rule case.

Given the belief that others are behaving the same, a strategic player in the conformity-rewarding institution will attempt to match the majority winner of the announcements of all individuals who precede him as well as those who follow. Strategic players in the conformity-rewarding institution should therefore act as public-information revealers. In fact Bayes-Nash equilibrium behavior predicts that this behavior should begin with the second decision maker whose decision should always follow the first. This prediction follows from the fact that the strategic player knows other strategic players will follow.

\section{Results}

\section{A. Data Examples}

Consider some examples of periods from the actual experiments. The columns represent the order in which individuals saw their draws and made their announcements. The first row is the private draw of the individual. A draw that suggests urn A is listed as "a" and a draw that suggests urn B is listed as "b." "12 The second row gives the announcements of the individuals as " $A$ " or "B" depending on the urn they chose. The relative odds of urn A given the private draw are given in row three. Row four gives the relative odds of urn A given the announcements heard up to that point, assuming that all previous announcements perfectly reveal the private signal.

In experiment 1 , period 10 , in which the individualistic institution was in effect, we observe a partial cascade. The eighth announcement reflects cascades behavior: his announcement is inconsistent with his private draw, but consistent with the majority of the preceding announcements. How-

\footnotetext{
${ }^{11}$ For a theoretical proof of existence of this equilibrium under a majority rule institution with sequential voting, see Eddie Dekel and Michele Piccione (1997) or Mark Fey (1998).

${ }^{12}$ The draw was actually either a RED ball (which suggests urn A) or a WHITE ball (which suggests urn B).
}

ever, the fourth announcement is consistent with the private draw, despite the predominance of preceding "B" announcements. ${ }^{13}$

Both measures of system performance are high in this period. The fully informed decision is " $\mathrm{B}$," which follows from the fact that seven private draws were "b" and three were "a." Therefore, the efficiency of systemic decisions, the proportion of decisions that match the fully informed decision is 0.8 . Furthermore, the information production quality is 0.96 .

INDIVIDUALISTIC INSTITUTION, EXPERIMENT 1, PERIOD 10

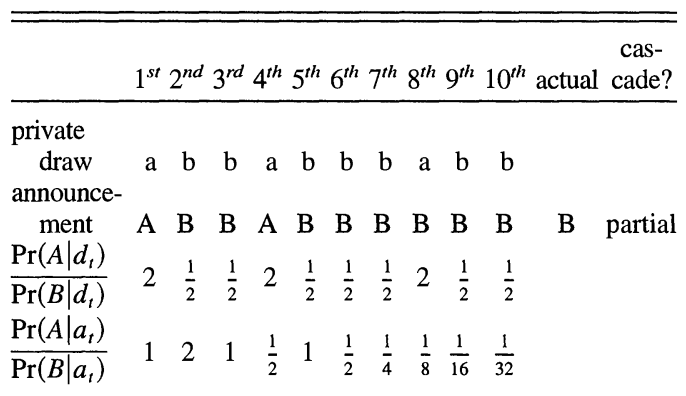

$a_{t}=$ announcements that have been made by position $t$, $d_{t}=$ private draw at position $t$.

In experiment 3 , period 30 , in which the majority rule institution is in place, there is no cascade. Every subject's announcement perfectly matches her private draw. In this case, the efficiency of systemic decisions is 1.0 , and the information production quality is 1.0 .

Majority Rule Institution, ExPeriment 3, Period 30

\begin{tabular}{lllllllllllllllll}
\hline \hline & $1^{\text {st }}$ & $2^{\text {nd }}$ & $3^{\text {rd }}$ & $4^{\text {th }}$ & $5^{\text {th }}$ & $6^{\text {th }}$ & $7^{\text {th }}$ & $8^{\text {th }}$ & $9^{\text {th }}$ & $10^{\text {th }}$ & $\begin{array}{c}\text { cas- } \\
\text { actual cade? }\end{array}$ \\
\hline $\begin{array}{c}\text { private } \\
\text { draw } \\
\begin{array}{c}\text { announce- } \\
\text { ment }\end{array}\end{array}$ & a & a & A & A & A & A & A & A & B & A & a & A & A & b & & \\
$\frac{\operatorname{Pr}\left(A \mid d_{t}\right)}{\operatorname{Pr}\left(B \mid d_{t}\right)}$ & 2 & 2 & 2 & 2 & 2 & $\frac{1}{2}$ & 2 & 2 & 2 & $\frac{1}{2}$ & & \\
$\frac{\operatorname{Pr}\left(A \mid a_{t}\right)}{\operatorname{Pr}\left(B \mid a_{t}\right)}$ & 1 & 2 & 4 & 8 & 16 & 32 & 16 & 32 & 64 & 128 & & \\
\hline
\end{tabular}

$a_{t}=$ announcements that have been made by position $t$, $d_{t}=$ private draw at position $t$.

\footnotetext{
${ }^{13}$ Given that "cascade" is not a very precise concept, especially when the posterior probabilities are equal, some may argue that round 10 is a full (rather than partial) cascade.
} 
TABle 2-Logit Regression Estimates

\begin{tabular}{|c|c|c|c|c|c|c|}
\hline & & $\mathrm{n}$ & $\alpha$ & $\beta$ & $\gamma$ & Log-likelihood \\
\hline \multirow[t]{5}{*}{ Individualistic } & Overall & 890 & $\begin{array}{c}0.062 \\
(0.124)\end{array}$ & $\begin{array}{c}1.142 \\
(0.088)\end{array}$ & $\begin{array}{c}3.046 \\
(0.225)\end{array}$ & -219.4749 \\
\hline & Exp1 & 280 & $\begin{array}{c}0.011 \\
(0.235)\end{array}$ & $\begin{array}{c}0.904 \\
(0.131)\end{array}$ & $\begin{array}{c}3.382 \\
(0.420)\end{array}$ & -62.4918 \\
\hline & Exp2 & 210 & $\begin{array}{c}-0.225 \\
(0.251)\end{array}$ & $\begin{array}{c}1.273 \\
(0.194)\end{array}$ & $\begin{array}{c}2.790 \\
(0.452)\end{array}$ & -54.8688 \\
\hline & Exp3 & 150 & $\begin{array}{c}0.564 \\
(0.387)\end{array}$ & $\begin{array}{c}1.708 \\
(0.358)\end{array}$ & $\begin{array}{c}4.266 \\
(0.858)\end{array}$ & -24.603 \\
\hline & Exp4 & 250 & $\begin{array}{c}0.155 \\
(0.220)\end{array}$ & $\begin{array}{c}1.149 \\
(0.167)\end{array}$ & $\begin{array}{c}2.794 \\
(0.385)\end{array}$ & -68.503 \\
\hline \multirow[t]{3}{*}{ Majority rule } & Overall & 380 & $\begin{array}{c}-0.001 \\
(0.212)\end{array}$ & $\begin{array}{c}0.523 \\
(0.109)\end{array}$ & $\begin{array}{c}3.89 \\
(0.342)\end{array}$ & -88.1445 \\
\hline & Exp2 & 150 & $\begin{array}{c}-0.112 \\
(0.277)\end{array}$ & $\begin{array}{c}0.624 \\
(0.161)\end{array}$ & $\begin{array}{c}3.139 \\
(0.450)\end{array}$ & -47.1357 \\
\hline & Exp3 & 230 & $\begin{array}{c}0.250 \\
(0.368)\end{array}$ & $\begin{array}{c}0.457 \\
(0.162)\end{array}$ & $\begin{array}{c}4.793 \\
(0.583)\end{array}$ & -35.8739 \\
\hline Conformity rewarding & Overall & 300 & $\begin{array}{c}-0.026 \\
(0.359)\end{array}$ & $\begin{array}{c}4.063 \\
(0.839)\end{array}$ & $\begin{array}{c}3.293 \\
(0.742)\end{array}$ & -26.1855 \\
\hline
\end{tabular}

Note: Standard errors are in parentheses.

In experiment 4 , period 10 , in which the conformity-rewarding institution is in place, dramatic cascade behavior occurs. All but three of the announcements are inconsistent with the private draw. The efficiency of systemic decisions is 0.3 and the information production quality is 0.06 .

CONFORMITY-REWARDING INSTITUTION, EXPERIMENT 4, PERIOD 10

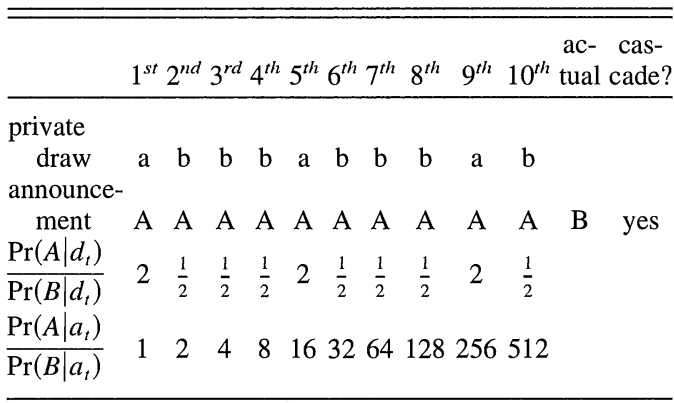

$a_{t}=$ announcements that have been made by position $t$, $d_{t}=$ private draw at position $t$.

\section{B. Statements of Results}

The cascade phenomenon described by Anderson and Holt is replicated in these experiments. A prevalence of cascade behavior is observed in the periods in which the individualistic institution is in place. As summarized by the following result, the phenomenon is observed even though different subject pools, instructions, and procedures are in place.

RESULT 1: The Anderson and Holt results are replicated for the individualistic institution. Furthermore, their results are robust to changes in payoffs and experimental settings.

\section{SUPPORT:}

In 77.5 percent of individualistic institution rounds, we observe cascade behavior; that is, we see reports that are inconsistent with the private draw, but are consistent with a pattern established by the predecessors. ${ }^{14}$

Of course it is important to make sure that a fundamental bias is not the explanation for the observation of cascades. Estimation of the General Decision Weight Model can reveal the occurrence of a bias toward one urn or the other. Table 2 presents the results of estimation of the General Decision Weight Model (equation 1). We do not find any bias toward one urn or the other.

\footnotetext{
${ }^{14}$ Note that in reporting the proportion of cascades, Anderson and Holt begin by eliminating rounds in which there is not "an imbalance of previous inferred signals." However, in reporting our results, we include all rounds, not just rounds in which an "imbalance" occurs.
} 
RESULT 2: The cascade phenomena is not due to an urn bias.

\section{SUPPORT:}

We find that, in equation $1, H_{0}: \alpha=0$ cannot be rejected at any reasonable significance level.

The next result establishes that behavior responds to institutions. In particular, using the measure of individual behavior found in Table 2, we rule out the simple patterns of behavior: the private-information revealer, the public-information follower, and the naive Bayesian. This result acquires additional significance in light of the fact that the instructions could be interpreted as having an institutional-neutrality bias. ${ }^{15}$

RESULT 3: Individuals do not exhibit constant behavior across all institutions as privateinformation revealers nor as public-information followers. Furthermore, we can reject the naive Bayesian pattern of behavior for the individualistic and majority rule institutions.

\section{SUPPORT:}

We reject the private-information revealer pattern: the hypothesis $\beta=0$ is rejected at the 1-percent significance level for the individualistic and majority rule institutions, and is rejected at the 5-percent significance level for the conformity-rewarding institution. We test the hypothesis that individuals are public-information followers. That is, we test $H_{0}: \gamma=0$ where $\gamma$ is the estimate of the coefficient on private information for positions 2-10 only, because the first mover every period has no public information, and therefore, cannot be a publicinformation revealer. We reject the null at all reasonable levels of significance. Lastly, we reject that individuals act as naive Bayesians $\left(H_{0}: \beta=\gamma\right)$ at all reasonable levels of significance for the individualistic and majority rule institutions.

We have shown that we can rule out theories which predict any of the three stylized patterns of behavior in which the institution has no ef-

\footnotetext{
${ }^{15}$ Constant across institutions were the instructions that subjects should try to guess the "urn that he or she thinks is more likely to have been used."
}

TABLE 3-EXPERIMENTAL RESUltS: OCCURRENCE OF INFORMATION CASCADES AND MEASURES OF SYSTEM PERFORMANCE

\begin{tabular}{|c|c|c|c|c|}
\hline \multirow[b]{2}{*}{ Institution } & \multirow[b]{2}{*}{$\frac{\beta}{\gamma}$} & \multirow{2}{*}{$\frac{\text { Cascades }}{\begin{array}{c}\text { Percent } \\
\text { occurrence }\end{array}}$} & Efficiency & \multirow[t]{2}{*}{$I P Q$} \\
\hline & & & Means & \\
\hline Individualistic & $\frac{\beta}{\gamma}=0.3749$ & 77.5 & 0.817 & 0.85 \\
\hline Majority rule & $\frac{\beta}{\gamma}=0.1344$ & 39 & 0.943 & 0.98 \\
\hline $\begin{array}{l}\text { Conformity } \\
\text { rewarding }\end{array}$ & $\frac{\beta}{\gamma}=1.2338$ & 96.7 & 0.75 & 0.70 \\
\hline
\end{tabular}

fect. Now we turn our attention to the differences in behavior and information production that can be attributed to the change in institution. Table 3 summarizes Results 4 and 5.

RESULT 4: Institutions change the information production of the system and the use of information by the individual. The pattern of individual behavior is that suggested by a theory of strategic agents:

1. Cascades observed can be ordered from least to most frequent depending on the institution that is in place: majority rule, individualistic, conformity rewarding.

2. Individual expressions (decisions and votes) reflect private information the most (in descending order): majority rule, individualistic, conformity rewarding.

3. The weight placed on publicly available information relative to the weight placed on privately available information increases as we change the institution from majority rule to the individual decision setting to the conformity-rewarding rule.

4. Under the conformity-rewarding institution, cascades begin with the second decision maker as predicted by Bayesian-Nash equilibrium behavior.

\section{SUPPORT:}

For each of the above results, we find that:

1. 39 percent of majority rule rounds, 77.5 percent of individualistic institution rounds, and 96.7 percent of conformity-rewarding rounds result in cascades or partial cascades.

2. 92 percent of announcements in majority 
rule rounds, 85 percent of announcements in individualistic institution rounds, and 64.7 percent of announcements in conformity-rewarding rounds are signal revealing.

3. Under majority rule, subjects place more than seven times as much weight on private information than on public information: $\frac{\beta}{\gamma}=$ 0.13 . Subjects place more than twice as much weight on private than on public information under the individualistic institution: $\frac{\beta}{\gamma}=0.37$. Only under the conformityrewarding institution do subjects place more weight on public than on private information: $\frac{\beta}{\gamma}=1.24$.

4. Consider the case in which the draw of the second person contradicts the announcement of the first person. In such cases the percentages of the second announcement that match the first announcement are 10.8 percent, 15.8 percent, and 72.2 percent for the individualistic, majority rule, and conformity-rewarding institutions, respectively.

We now explore the additional measures of system performance. To measure the efficiency of systemic decisions, we calculate the proportion of decisions that coincide with the fully informed decision, the decision that an omniscient agent would make if he knew the entire sequence of signals. Periods in which the posteriors used in calculating the fully informed decision equal 0.5 were omitted.

RESULT 5: We can rank the institutions in the order of highest to lowest efficiency of systemic decision: majority rule, individualistic, and conformity rewarding. Similarly, the institutions in the order of highest to lowest information production quality are majority rule, individualistic, and conformity rewarding.

\section{SUPPORT:}

The means of the proportions of systemic decisions that match the fully informed decision for the individualistic, majority rule, and conformity-rewarding institutions, respectively, are $0.82,0.94$, and 0.74 (Table 3 ). In fact, with only two exceptions, the efficiency of systemic decision equals one under the majority rule institution. Under the individualistic institution, we see an increase in the number of efficiencies that fall below 0.5 . Under the conformity-rewarding institution, we find the efficiencies are lower, on average, than the other institutions. Furthermore, we find high variation: all the efficiencies lie at one extreme or the other (greater than or equal to 0.8 or less than or equal to 0.1 ).

The average information production quality is 0.98 under the majority rule institution (Table 3). This is not surprising given that 92 percent of the announcements are signal revealing. The average absolute difference between the posterior probabilities given the private signals and the posterior probabilities given the announcements under the individualistic institution is more than twice as large as under the majority rule institution, and is reflected by a quality of information production of 0.85 . Lastly, under the conformityrewarding institution, the average absolute difference is twice that of the individualistic institution: 0.30 , and therefore, the quality of information production is 0.70 . In fact, we find 20 percent of the periods have posteriors that differ by more than 0.5 points.

\section{Conclusion}

While keeping the technologies of communication constant, we examine the effects on information aggregation and production under three different institutions: the individualistic institution, which is that studied by Anderson and Holt (1997), the majority rule institution, and the conformity-rewarding institution. The results of Anderson and Holt replicate (Result $1)$. In our experiments we observe the phenomena they report. The experiments reported here reflect a different subject pool, different procedures, computerized processes, different payoffs, and many other things. It follows that the Anderson and Holt discovery is robust to changes in these classes of variables.

We find marked changes in individual behavior and information production due to the change in institution. Individual decisions change as institutions change and examination of these changes helps us further narrow the class of explanations for cascade behavior. Individuals do not follow simple rules of thumb such as mimicking behavior or full truthful revelation. The ability to rule these out follows from the changes of individual rules in response to the changes of institution. We can also rule 
out a preference for conformity and nonequilibrium Bayesian behavior (Result 3).

Furthermore, the differences in behavior due to the institution follow an understandable pattern. The weight that individuals place on public information, relative to private information, in making decisions is highest under the conformity-rewarding institution; indeed, this is the only institution under which public information is weighed more than private information. At the other extreme, under the majority rule institution, the least weight is put on the public information relative to the private information (Result 4).

These patterns are consistent with a theory of strategic decision makers such as BayesianNash equilibrium. Clearly, there is much work to be done in developing a model of how individuals use the public information, together with their private information, and their beliefs about the behavior of others to come to their decisions.

The pattern of results suggest two important messages. The first message is that patterns of conformity widely observed in social behavior can result from a deeper motivation than simply a "desire to conform." Decisions of others contain information that is important for incorporation with "own decisions." Notice that even though cascades exist, they are not overwhelmingly inefficient. Indeed, "going along with the group" is not all bad. It reflects an element of wisdom. For example, under the individualistic institution, the system efficiency would be 71.6 percent if all individuals made decisions according to their private information alone. If they were naive Bayesians the system efficiency would have been 83.1 percent. The actual efficiency was 81.7 percent. Thus, the naive Bayesian behavior, which produces substantial cascades, also produces a substantial improvement in decisions from a social point of view. Interestingly enough, the fact that actual systemic efficiency falls short of that of naive Bayesians suggests that individuals do not pay enough attention to others.

The second message is that care must be taken in the design of collective decision process. The rules of the institution make a difference. In terms of information production, an outside observer learns the most from observing a majority rule process and the least from a conformity-rewarding process (Result 5). These differences are understandable in terms of rational and strategic positions in which the rules place individuals.

\section{REFERENCES}

Anderson, Lisa R. and Holt, Charles A. "Information Cascades in the Laboratory." American Economic Review, December 1997, 87(5), pp. 847-62.

Aronson, Eliot; Wilson, Timothy D. and Akert, Robin M. Social psychology. New York: Addison Wesley Longman, 1997.

Asch, Solomon E. "Effects of Group Pressure upon the Modification and Distortion of Judgements," in Eleanor E. Maccoby, Theodore M. Newcomb, and E. L. Hartley, eds., Readings in social psychology. New York: Holt, Rinehart \& Winston, 1958, pp. 174-83.

Banerjee, Abhijit V. "A Simple Model of Herd Behavior." Quarterly Journal of Economics, August 1992, 107(3), pp. 797-817.

Becker, Gary S. "A Note on Restaurant Pricing and Other Examples of Social Influences on Price." Journal of Political Economy, October 1991, 99(5), pp. 1109-16.

Bikhchandani, Sushil; Hirshleifer, David and Welch, Ivo. "A Theory of Fads, Fashion, Custom, and Cultural Change as Informational Cascades." Journal of Political Economy, October 1992, 100(5), pp. 992-1026. . "Learning from the Behavior of Others: Conformity, Fads, and Informational Cascades." Journal of Economic Perspectives, Summer 1998, 12(3), pp. 151-70.

Dekel, Eddie and Piccione, Michele. "On the Equivalence of Simultaneous and Sequential Binary Elections." Northwestern University Center for Mathematical Studies in Economics and Management Science Discussion Paper No. 1206, December 1997.

Fey, Mark. "Informational Cascades and Sequential Voting." Mimeo, University of Rochester, March 1998.

Grether, David M. "Bayes Rule as a Descriptive Model: The Representative Heuristic." Quarterly Journal of Economics, November 1980, 95(3), pp. 537-57.

Karni, Edi and Levine, Dan. "Social Attributes and Strategic Equilibrium: A Restaurant 
Pricing Game." Journal of Political Economy, August 1994, 102(4), pp. 822-40.

McKelvey, Richard D. and Palfrey, Thomas R. "An Experimental Study of Jury Decisions." California Institute of Technology Social Science Working Paper No. 1034, 1998a.

. "Quantal Response Equilibria for Extensive Form Games." Experimental Economics, 1998b, 1(1), pp. 9-41.

Plott, Charles R. and Smith, Jared. "Instability of Equilibria in Experimental Markets: UpwardSloping Demands, Externalities, and FadLike Incentives." Southern Economic Journal, January 1999, 65(3), pp. 405-26.
Schachter, Stanley. "Deviation, Rejection and Communication." Journal of Abnormal and Social Psychology, 1951, 46, pp. 190-208.

Smith, Lones and Sørensen, Peter. "Pathological Outcomes of Observational Learning." Econometrica, March 2000, 68(2), pp. 371-98.

Willinger, Marc and Ziegelmeyer, Anthony. "Are More Informed Agents Able to Shatter Information Cascades in the Lab?" in Patrick Cohendet, Patrick Llerena, Hubert Stahn, and Gisele Umbhauer, eds., The economics of networks: Interaction and behaviours. Heidelberg: Springer-Verlag, 1998, pp. 291-305. 